\title{
A3R CONSTRUCCIÓN DE MODELOS DE GÉNERO A www.aibr.org PARTIR DE TEXTOS DE LA TRADICIÓN ORAL EN EXTREMADURA (ESPAÑA)
}

Sebastián Díaz Iglesias

Profesor-tutor de Antropología en la UNED (España). Dirección de contacto: C/ Islas Baleares, $n^{\circ} 30$, 10001 Cáceres (España). E-mail: seba@piornal.net.

\begin{abstract}
Resumen
La tradición oral musical ha constituido un fuerte apoyo para la transmisión y consolidación de los modelos tradicionales de género, que asociaban a los hombres al poder y a las esferas de la producción y lo público, mientras las mujeres reflejaban la subordinación y el sometimiento, quedando asociadas a las esferas de la reproducción y lo doméstico.

De igual manera que la música de tradición oral ha sido determinante en el mantenimiento de estos modelos, puede serlo en su transformación hacia modelos de género más igualitarios hacia los que hoy día tiende nuestra sociedad.
\end{abstract}

Palabras clave

Música, folklore, género, tradición oral

\begin{abstract}
The musical oral tradition has strongly supported the transmission and consolidation of the traditional models of gender, which associated men to power and to the production and public fields while women showed subordination and submission, being associated to the reproduction and domestic fields.

In the same way the music of oral tradition has been essential in the consolidation of these models, it can be essential in its transformation towards the more egalitarian models of gender towards which society is moving today.
\end{abstract}

\section{Keywords}

Music, folklore, gender, oral tradition

\section{Introducción}

$\mathrm{T}$ odos somos conscientes de que pertenecemos, formamos parte o nos consideran adscritos a un género, por diferenciación con los miembros de los otros géneros. $Y$ decimos género no como equivalente a sexo en tanto que construcción biológica y natural, sino género en tanto que "construcción sociocultural" (Gutiérrez Lima, 1999: 45). Damos pues en este texto prevalecía al género sobre el sexo, a lo cultural sobre lo natural. 
Tampoco queremos que se entienda "identidad de género", como "identidad del nosotras" o "identidad de la mujer". El concepto de género trasciende a lo exclusivo femenino. Podemos hablar de género como de una "dimensión social y cultural de las relaciones, que tienen como referencia el hecho de que la especie humana es sexuada" (Del Valle, 1997: 11) y señalar que la antropología del género, por tanto y como señala Thurén, "no estudia solamente a las mujeres, sino a las relaciones entre las mujeres y los hombres, y eso es el sistema de género" (1992: 47). Pretendemos pues establecer, a partir de un análisis de textos de canciones, la posición de hombres y mujeres en nuestra sociedad tradicional, la extremeña, preferentemente vinculada a entornos rurales, sus comportamientos culturalmente determinados y cómo todo ello se ve reflejado en la música.

A la hora de definir modelos de género, la misma concepción androcéntrica de la Antropología y otras ciencias sociales nos sitúa ante una primera e importante diferenciación. Como asevera Isidoro Moreno refiriéndose a la presencia de hombres y mujeres en estas ciencias, "Los hombres aparecen como los únicos sujetos sociales que hacen la historia, o la sufren. Que actúan cambiando el mundo, o adaptándose a él. Construyendo la sociedad, ejerciendo el poder o rebelándose ante él, teniendo estrategias económicas, protagonizando los rituales religiosos, emigrando, filosofando, creando arte..." (1991: 620). En las sociedades rurales, que son las que aquí nos ocupan, la literatura antropológica ha tendido a hacernos partir de una configuración general del género masculino asociada con el trabajo, obligación sin paliativos de los hombres, vinculados a la esfera de la producción y a las relaciones sociales que esta conlleva, ocupar los espacios públicos, dominar a la naturaleza, propiciar a lo sobrenatural, etc. Para el género femenino quedaría la reproducción, y atributos sociales que esta lleva aparejados, como la esfera doméstica, el espacio privado, la ausencia de la vida social extrafamiliar a la que sólo se accedería por imperativos reproductivos (Moreno Navarro, 1991) Partimos de esta manera de una idea en torno a las estructuras de género en ámbitos rurales marcada por las asimetrías evidentes, a partir de las cuales se han generado modelos de hombre y mujer muy característicos, sobre los que han escrito en el caso español diferentes autores (Méndez, 1991; Moreno, 1991; Gilmore, 1994; Talego, 1999), y que básicamente remiten a la asociación hombre/producción-público-poder y mujer/reproducción-privadosubordinación, algo que quedan bien patente como veremos en los textos de la tradición musical oral. Rosario Otegui (2001) sostiene que esa asociación de la mujer con lo privado no se puede defender si pensamos en la presencia de estas por ejemplo en las iglesias, lugares claramente públicos, o en la calle, lugar por excelencia de reunión femenina en torno a labores, generalmente de costura. Si bien este hecho no se refleja claramente en los textos de las canciones, sí emerge de otras maneras, como el hecho de que los cantos religiosos (cantos de Semana Santa, vinculados a santos, a la Virgen o a Cristo, rogativas, etc.) sean cantos colectivos (algo que remite fuertemente a la esfera de lo público) y plenamente femeninos.

Hay que señalar no obstante, en las últimas décadas hemos asistido a un importante incremento en la producción antropológica en la que la mujer ha adquirido un protagonismo relevante en cuanto a objeto de estudio y análisis, especialmente en el ámbito de la España rural (Brandes, 1991; Gala 
González, 1999, Talego, 1996, 1999), pero también de las migraciones (Gregorio Gil, 1999), la posición de las mujeres en ámbitos rituales (Bullen, 1999) y en otras culturas (Martín Muñoz, 1995; Provanzal, 1999), así como referida a los cambios tan considerables que últimamente se están generando en la pautas de relación entre géneros (Mozo, 1992; Talego, 1999). Ciertamente las estructuras de género están sometidas a un proceso de transformación que en determinadas parcelas camina hacia un acercamiento entre los valores socialmente aceptados para uno y otro género, según recoge Mozo González: "En la actualidad asistimos a cambios importantes en la construcción social del género. Una parte de los valores que tradicionalmente se asociaban al género masculino, han pasado a ser valores válidos para hombres y mujeres" (1992: 149). Si bien estos cambios constituyen un ámbito escasamente reflejado en los textos musicales, construidos generalmente en épocas pasadas, sí se ponen de manifiesto en su interpretación y la tendencia a ciertas modificaciones en los ya existentes, así como a apropiarse un género de textos tradicionalmente atribuibles al otro.

Realizadas estas consideraciones teóricas que pretenden servir de soporte al análisis posterior, nos disponemos a realizar un recorrido por textos de canciones tomados de la tradición oral y su relación con la definición de las estructuras de género, iniciando éste por los cantos de los más pequeños, las canciones de la infancia.

\section{Textos y contextos de género}

Para empezar con las músicas del ciclo de la vida, y refiriéndonos más concretamente a las nanas o canciones de cuna, nos situamos ante un repertorio melódico monótono y repetitivo, caracterizado por las típicas fórmulas a base de monosílabos, regidos por la letra ene (na, na) y por la erre (ro, ro), así como por combinaciones de vocales (ea, ea). En cuanto a los contenidos de los textos, a las continuas peticiones al niño para que duerma, hay que añadir las alusiones al "coco", ser imaginario que viene a llevarse a los niños que duermen poco, y también a las ocupaciones de la madre que queda claramente vinculada a la esfera de lo doméstico, como se puede leer en el siguiente texto de una nana.

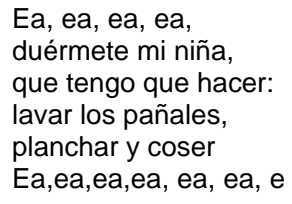

La asociación entre mujeres y el cuidado de los hijos se pone de manifiesto en el tan mantenido regalo de muñecas a las niñas, para que estas reproduzcan dirigidos a éstas, comportamientos de su madre hacia ellas.

Tu eres una niña buena

y yo te voy a regalar

una muñeca muy linda 
para con ella acostar

Que el cuidado de los pequeños es una tarea por entero de las madres queda bien patente en este fragmento de una nana:

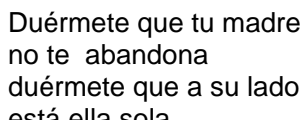

está ella sola.

Las canciones infantiles o canciones con las que los niños acompañan a muchos de sus juegos, constituyen un segundo exponente de la tradición oral para marcar diferencias de género. Su valor de canción social las otorga un peso relativo junto al de las enseñanzas en casa y en la escuela, a la hora de empezar a construir ideas de género en los pequeños.

Son niñas las que principalmente juegan o han jugado a la comba, al corro y a la goma, practican o han practicado juegos de palmas, y cantan canciones, frente a los niños que reafirman su identidad precisamente no realizando estos juegos de manera espontánea, y aún en caso de practicarlos en alguna ocasión concreta ${ }^{1}$, nunca cantando. Aún hoy día son manifiestas las expresiones de rechazo por parte de los niños a esos "otros" de su sexo que gustan de estos juegos tradicionalmente de niñas, los practican a un buen nivel de ejecución y además, interpretan las canciones que llevan aparejadas. Estos niños son tildados de "maricas", vocablo que les excluye de su grupo de género. Hay que señalar asimismo que algunos niños, han utilizado este tipo de prácticas para reproducir su condición de machos, introduciéndose en el juego, incluso en el canto, para desde dentro ridiculizarlo ante la mirada atenta de sus amigos; para ello, saltan mal exagerando los movimientos, se caen violentamente, cantan desafinando de manera ostensible y tras un rato de parodia, dejan el juego con expresiones que claramente den a entender que si no lo hace bien no es por la dificultad del juego, sino simplemente, porque es un juego de niñas.

Un análisis etnolingüístico de las canciones infantiles nos permite hablar de una sociedad tradicional en la que hablar de matrimonio es hacerlo de un tipo de emparejamiento entre un hombre y una mujer que constituye el estado ideal al que debe aspirar esta última. En esta sociedad la mujer era educada hacia el matrimonio desde la misma infancia, algo que se constata en muchas letras de las canciones con las que las niñas acompañaban sus juegos:

$\begin{array}{ll}\begin{array}{l}\text { Yo soy la viudita } \\ \text { del Conde Laurel } \\ \text { que quiero casarme } \\ \text { y no sé con quién }\end{array} & \begin{array}{l}\text { El capitán de un barco } \\ \text { me escribió un papel } \\ \text { que si yo quería } \\ \text { casarme con él }\end{array} \\ \begin{array}{l}\text { Arroz con leche me quiero casar } \\ \text { con una señorita de este lugar }\end{array} & \begin{array}{l}\text { Quién dirá la carbonerita } \\ \text { que sepa coser, que sepa bordar } \\ \text { que sepa la tabla de multiplicar }\end{array} \\ \text { quién dirá que la del carbón, } \\ \text { quién dirá que yo estoy casada } \\ \text { quien dirá que yo tengo amor }\end{array}$

\footnotetext{
${ }^{1}$ Hay que señalar que desde inicios de los años noventa, con la presencia de maestros especialistas en Educación Física en todos los centros educativos, y ésta como una asignatura más de un currículo con la coeducación como regla transversal ineludible, los niños realizan, por ejemplo, juegos de comba o de corro, aunque no es corriente que a partir de cierta edad, ocho o nueve años, canten sus canciones y aún menos los repitan fuera de la sesión de "Gimnasia", como ellos dicen para disgusto de sus profesores, cosa muy habitual entre las niñas.
} 

La viudita, la viudita,
la viudita se quiere casar
con el conde, conde Cabra,
conde Cabra lo quiere dejar

\author{
Tu marido y el mío \\ van a por leña \\ y se vienen huyendo \\ de la cigüeña
}

Se menciona incluso a San Antonio, personaje sagrado ligado a la fecundidad y la reproducción, valor social de gran importancia que siempre debía darse en el seno del matrimonio:

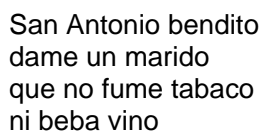

La mayor parte de estos textos presentan diálogos en las que aparecen al menos dos personajes: un chico pretendiente y una chica pretendida. Las niñas en sus juegos reproducen estas situaciones de galanteo pasando de un personaje a otro y dramatizando a veces, especialmente en los juegos de corro, acciones presentes en el texto, a modo de preparación para cuando, pasados unos años, en realidad deban enfrentarse a tales situaciones. Los textos en los que la niña habla por boca de varón expresan claramente la posición privilegiada de éste, que puede elegir entre todas las chicas cuál ha de ser su esposa (en el juego, a qué otra niña escoge para formar pareja), frente a la actitud pasiva de la elegida:

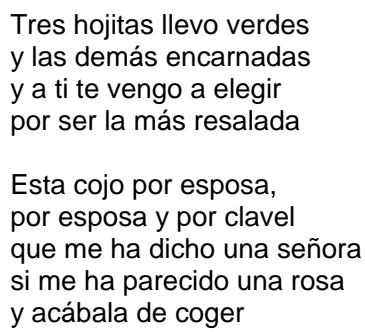

\author{
Muchas gracias jardinero \\ por el gusto que has tenido \\ tantas niñas en el corro \\ y a mi sola me has escogido \\ Siendo yo militar \\ de una chiquilla me enamoré \\ la cubrí con mi capa \\ y al campamento me la llevé
}

La preparación de la niña dirigida a la esfera doméstica y la consideración del hombre ligado a la esfera de la producción, son evidentes en los textos de las canciones infantiles, así éstos asocian a la mujer tareas como ir a la compra, hacer la comida, coser y bordar, u ocupaciones asociadas a las flores, como jardinera, mientras al hombre se le relaciona con actividades como vender y profesiones como la de albañil, boticario, militar, etc.

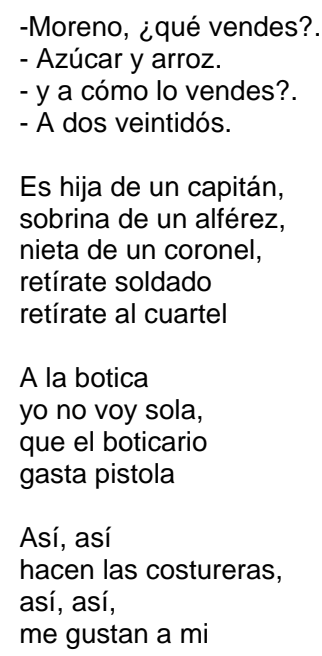

\author{
Salga usted madre \\ con el dinero, \\ compre carbones \\ al carbonero
Albañil de mi vida, ¡cuánto te quiero! de la torre más alta caigas al suelo
Y las mujeres cogen la plancha para planchar el vestidito de su mamá
Al levantar una lancha una jardinera vi regando sus lindas flores \\ y al momento la seguí
}


Las canciones de quintos, tradicionalmente tonadas masculinas por excelencia, también nos permiten referirnos a textos que remiten a las asimetrías de género. Generalmente en estos cantos son constantes las alusiones a las mujeres centrales en la vida de un joven, por un lado la madre, incluso la abuela, y por otro la novia. El hecho de que sean la novia y la madre las únicas asociadas a emociones, sentimientos y momentos de exaltación de la afectividad, frente al padre al que nunca se cita en estas situaciones de pesar y llanto, remite como en otros casos a modelos tradicionales de género. Los siguientes fragmentos de coplas son un exponente claro de esta afirmación:

El novio cuando se va
la novia lloraba a gritos,
se dicen unas a otras
mañana se van los quintos
Las madres son las que lloran
que las novias ni lo sienten
se quedan cuatros chavales
y con ellos se divierten
De que soy quinto mi madre llora
la mi morena, la dejo sola,
la dejo sola, la he de dejar,
la mi morena qué tal la irá

\section{El día de mi sorteo estabas en la ventana y al oír mi mala suerte te caíste desmayada}

Las novias son las que lloran que las madres no lo sienten se quedan con sus maridos acostás a lo caliente

Es de destacar el papel de otra mujer, la abuela, con autoridad suficiente como para conseguir librar al nieto de la mili:

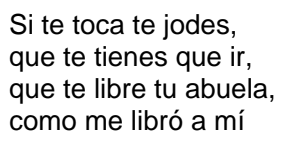

Estas alusiones a la presencia y el poder de las abuelas en situaciones delicadas para el grupo de parentesco, como la marcha de uno de sus miembros, limitados a contextos privados, por encima del poder y la autoridad de padres y abuelos, manifiestos en la esfera de lo público, deja entrever, por un lado, la importancia de los años en las relaciones de poder, en otro tiempo, y por otro, la posición de las mujeres en estas relaciones, en modo alguno subordinado a los hombre, al menos de una manera latente. Las relaciones con la otra mujer repetidamente mencionada en los textos, la novia, se presentan de una manera incierta e inestable. Nuevamente sobresalen modelos tradicionales de género que definen a la mujer como un ser vulnerable, sometida al hombre y a sus designios. De esta manera, el temor que manifiesta el joven que se marcha, más que a lo desconocido de su destino, es a la fragilidad de su novia ante situaciones de galanteo por parte de otros jóvenes que se quedan. Esta fragilidad y la incertidumbre del noviazgo quedan patentes en textos como los siguientes:

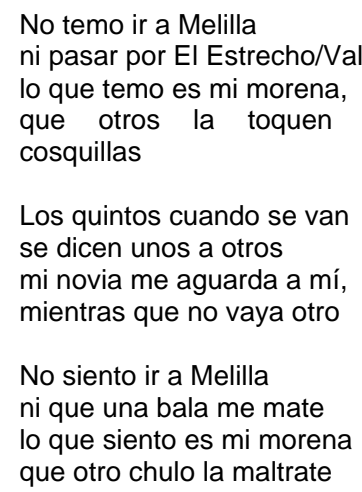

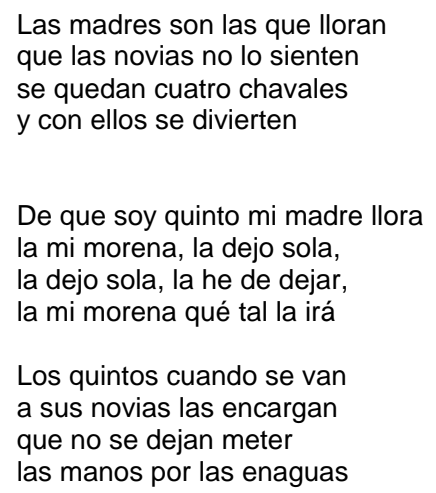




\author{
Quintos del 63 \\ y no tenemos envidia \\ que llevamos por delante \\ al de Marcela La Rubia
}

Quintos del 69
todos con mucha alegría
que llevamos por delante
al de Casimira Díaz

También era corriente hacer una sola copla para aquellos mozos de la misma familia que tuvieran el mismo apodo por parte de padre (primos paralelos patrilaterales).

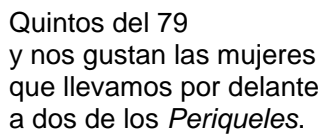

No podríamos dejar de lado los cantos de boda, en un análisis de la reproducción de modelos de género en textos de la tradición oral. Sin duda el matrimonio ha supuesto en nuestra sociedad, y en gran medida aún sigue suponiendo, "el triunfo del modelo de orden social que una comunidad quiere para sí" (López García, 2002: 67), y, especialmente para las mujeres en entornos rurales, un estado ideal al cual debe tender.

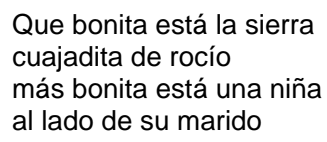

Un análisis de los textos de canciones de boda nos ofrece nuevamente, una constatación de los modelos tradicionales de hombre y mujer. Tanto es así que resulta recurrente la presencia en estos textos de símbolos que remiten a la virginidad que debe acompañar a la novia hasta el momento de su boda. Uno de esos símbolos es el color blanco, "ramito blanco", "ramito de azahar", "blanca paloma". La pureza, como sinónimo de virginidad, aparece ligada a símbolos religiosos como la Virgen, los Ángeles y Angelitos, y el agua bendita, símbolos que, por otra parte, nos informan de la presencia determinante de la religión católica en estos rituales, algo también manifiesto por las constantes referencias a la iglesia y al cura.

La fragilidad, la sensibilidad, la estética, son también atributos asociados a la mujer, algo que resulta observable en las muchas metáforas que podemos encontrar en estos textos y que se refieren a ésta, la mujer, como una delicada flor: amapola, clavellina, azucena, rosita temprana, bella flor, ramito de auré (laurel), ramito de perejil, incluso como un vaso de cristal o espejo; el mismo uso de los diminutivos nos remite a estos conceptos de pequeño, sensible y dulce (rosita, ramito, angelito, pajarito) vinculados a este género.

Ese ramito blanco que has estrenao significa pureza, la que has llevao, la que has llevado niña, la que has llevao, ese ramito blanco que has estrenao

\author{
Un coro de angelitos esta mañana \\ a tu ventana niña todos cantaban, \\ con ramito de flores todos repiten \\ los recién casaditos sean felices \\ Esta mañana temprano \\ tomaste agua bendita \\ la última de soltera \\ la primera casadita
}




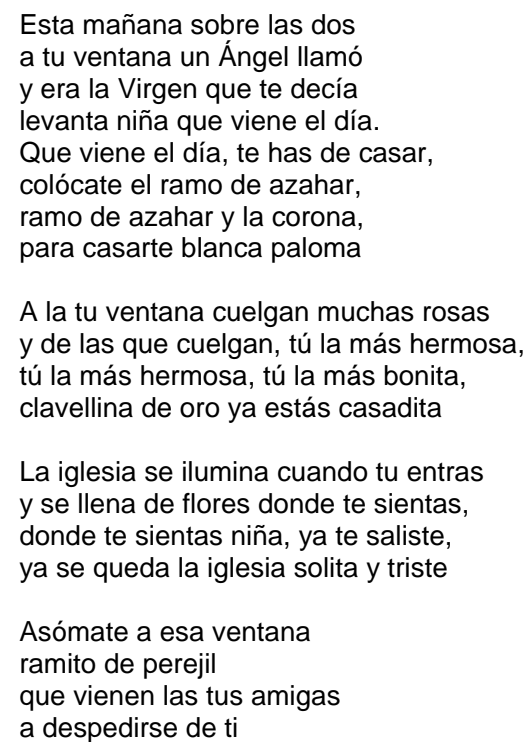

Pa tu marido buena serás que llevas puesto el ramo de azahar, ramo de azahar y la corona, para casarte blanca paloma

\author{
La mejor clavellina de tus claveles, \\ ninguna tan hermosa como tú eres, \\ como tú eres niña, como tú eres, \\ la mejor clavellina de tus claveles \\ La luna se va a poner \\ hacen sombras tus tejados, \\ yo me voy a recoger \\ clavelito colorado \\ Ten cuidado con la novia \\ cuando se vaya a acostar \\ no se caiga de la cama \\ que es un vaso de cristal
}

La subordinación de la mujer al hombre queda bien patente en textos como el que nos habla de servirle la comida o quitarse el vestido a los pies sus pies, en señal de sumisión a éste. La sumisión es tal que el matrimonio supone para la mujer un paso decisivo en el que pierde la propia libertad, quedando prisionera de su nueva posición de mujer casada.

Otra de las mujeres importantes en una boda, la madrina, también queda vinculada a la esfera doméstica.

$\begin{array}{ll}\begin{array}{l}\text { Coge niña esa manzana } \\ \text { repártela por la mesa } \\ \text { da primero a tu marido } \\ \text { que así lo manda la iglesia }\end{array} & \begin{array}{l}\text { Esta mañana temprano } \\ \text { estrenaste un vestido } \\ \text { y te lo has ido a quitar } \\ \text { a los pies de tu marido }\end{array} \\ \begin{array}{l}\text { Por un sí que dio la novia } \\ \text { a la puerta de la iglesia, } \\ \text { por un sí que dio la novia } \\ \text { entró libre y salió presa }\end{array} & \begin{array}{l}\text { Las sábanas de la novia } \\ \text { están bordadas en oro } \\ \text { que las bordó la madrina } \\ \text { para el día del casorio }\end{array}\end{array}$

Despídete de tus padres y también de tus vecinos que te vamos a llevar a dormir con tu marido

Es al marido al que, por otro lado, se le encomienda el cuidado y la protección de la esposa. Asimismo, se piensa en un marido asociado a la esfera de la producción, encargado de proveer la casa de riqueza material (dinero), frente a la mujer que recibe esta riqueza a la que responde con otra forma de riqueza, la espiritual.

\author{
Por Dios te pido José, \\ por la parte que me toca, \\ que cuides bien a María \\ como tu querida esposa
}

\author{
El novio le dio a la novia \\ un anillo de oro fino, \\ ella le dio su palabra \\ que valía más que el anillo
}

Hay que señalar, no obstante, como ya ocurriera en el caso de los quintos, la posición relevante de las mujeres adultas en las estructuras de poder, algo que se pone de manifiesto en muchos casos en la toma de decisiones en torno al establecimiento de una relación entre dos jóvenes, tanto en los inicios de un noviazgo, cuya última palabra la tenía generalmente la madre de la futura novia, como en los inicios del matrimonio en los que la madre del recién casado cobraba una especial relevancia. 


\author{
Aquí me pongo a cantar \\ con el pie puesto en un leño \\ para que digas a tu madre \\ que si me quiere por yerno \\ Salga la madre del novio \\ un poquito más afuera \\ a recibir a su hijo \\ y a reconocer a la nuera
}

\author{
Escuche usted bien tía María \\ aquí vengo a lo que vengo \\ si usted me da la su hija \\ yo le doy el mejor yerno. \\ Salga la madre del novio \\ a recibir a la nuera \\ que muchos la han pretendido \\ y su hijo se la lleva
}

En una de las coplas características de estas canciones se pone de manifiesto un aspecto crucial en la sociedad tradicional, cual es el valor social de la fecundidad:
A los recién casaditos,
Dios les dé mucha fortuna,
y que otro año por ahora,
tengan un niño en la cuna

La necesidad de brazos para el trabajo del campo obligaba a los matrimonios a cargarse de hijos con los que hacer frente a las demandas de la tierra, de ahí la importancia que se otorgaba a la reproducción y a la fertilidad de las mujeres. El matrimonio como forma de regulación de la procreación, tenía como uno de sus principales objetivos precisamente la reproducción, de ahí que el paso socialmente deseable inmediatamente posterior a la boda en una pareja recién casada era el embarazo de la mujer. Una mujer que tardaba en quedar preñada, era víctima de la crítica social y "pasaba a formar parte, junto con los mozos viejos y las solteronas, de lo antinatural y lo antisocial" (López García, 2002: 42).

Concluimos este repaso de los textos de las canciones de tradición oral y la presencia en ellos de modelos de género, con las llamadas canciones de ronda.

Existen diversas coplas utilizadas en este tipo de cantos que hablan del acto mismo de rondar, en una concepción clásica de rondas como el arte de cantar a las mujeres, en las que estas actúan como receptoras de la música y nunca como intérpretes.

\author{
En el medio de la plaza \\ hay una piedra redonda \\ donde se sientan los mozos \\ las noches que van de ronda \\ A la puerta de mi novia \\ un amiguito canto \\ a la puerta de la suya \\ razón es que cante yo
}

$\begin{array}{ll}\begin{array}{l}\text { Ya sé que estás acostada } \\ \text { pero dormidita no, } \\ \text { ya sé que estarás diciendo } \\ \text { ese que ronda es mi amor }\end{array} & \begin{array}{l}\text { Asómate a esa ventana } \\ \text { cara de limón florido } \\ \text { no digas por la mañana } \\ \text { que ha rondarte no he venido }\end{array} \\ \begin{array}{l}\text { Dale compañero, dale } \\ \text { a la guitarra que suene, } \\ \text { que está muy lejos la cama } \\ \text { donde mi morena duerme }\end{array} & \begin{array}{l}\text { Tamboril, tamborilito } \\ \text { yo te tengo que romper } \\ \text { que a la puerta de mi novia } \\ \text { no quisiste tocar bien }\end{array}\end{array}$

Así como estas rondas, que suelen asociarse a momentos de galanteo, de canto a la belleza, de petición, de ofrecimiento siempre dirigido a un ser humano, en este caso la mujer galanteada, como se recoge en sus textos, son generalmente interpretadas por hombres, a las mujeres les corresponden cantos de exaltación de la belleza y las bondades, de petición y de ofrenda a seres sobrenaturales, a Vírgenes, Santos y símbolos religiosos. Son generalmente las mujeres las que con sus cantos se dirigen a estos seres sacros, dentro de la iglesia o en procesiones, quizá como 
extensión de su actividad al mundo de lo público, pero no al mundo de lo público y real, sino al de lo público y sobrenatural ${ }^{3}$.

\author{
Todas nos presentamos \\ con humildad \\ a cantar esta rosca \\ a San Sebastián \\ Ere purísima Virgen \\ madre del divino Verbo \\ hoy venimos muy gozosas \\ a cantar tu nacimiento
}

\author{
A las mozas que cantan \\ aquí esta rosca \\ y al Jarramplas que toca \\ danos la Gloria \\ Al párroco, mayordomo \\ y demás autoridades \\ estas tus hijas pedimos \\ que nunca nos desampares
}

\author{
A ti, reina del Cielo, \\ se eleva nuestra voz, \\ somos tus hijas, \\ os imploramos, hermosa reina, tu \\ bendición.
}

Es frecuente la utilización de nombres de instrumentos en las canciones de ronda en su acepción originaria de ronda a la mujer, y muy recurrente la presencia de mujeres, de manera genérica o concretada en nombres propios, en estas coplas. También podemos encontrar metáforas y símiles en los textos de las canciones que remiten a la asociación: instrumentos musicales/mujer ${ }^{4}$, lo que nos permite hablar nuevamente de modelos tradicionales de género en los que, como ya hemos mencionado para otros casos, se asocian a la mujer cualidades como la sensibilidad o la estética, propios de ámbitos musicales. Por otro lado se presentan prohibidos atributos de la mujer como sinónimos del Mal, caso de los pechos, metafóricamente un cuchillo asesino.

\author{
Las cuerdas de mi guitarra \\ ya te diré las que son \\ María, Teresa y Juana \\ Dolores y Encarnación \\ Al que toca la guitarra \\ tres puñalás le daré \\ y los cuchillos serán \\ los pechos de una mujer
}

\author{
Dame de tu pelo rubio \\ cuerdas para mi guitarra \\ que se me ha roto la prima \\ la segunda y la tercera \\ Al que toca la guitarra \\ del cielo le caiga un rayo \\ y se le vuelva una niña \\ de catorce a quince años
}

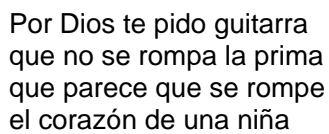
que no se rompa la prima el corazón de una niña

\section{La idea de mujer como ser con poderes mágicos, capaces de matar a un hombre o hacerle} enloquecer es recurrente en los textos de las canciones.

\author{
Si me quieres dímelo \\ y si no dame veneno \\ que no es primera dama \\ que da veneno a su dueño \\ Manojito de claveles \\ me parecen tus pestañas \\ cada vez que los miro \\ se me clavan en el alma
}

\author{
Todas las que son morenas \\ tienen un mirar extraño \\ que cuando miran a un hombre \\ le quitan de vida un año
}

\author{
Tienes unos ojos niña \\ traicioneros y ladrones \\ que salen a los caminos \\ y roban los corazones
}

$\begin{array}{ll}\text { Al primer toque de misa } & \text { Unos ojos negros fueron } \\ \text { te vistes y te compones } & \text { causa de mi enfermedad } \\ \text { y te vas la calle arriba } & \text { no quiero más ojos negros } \\ \text { robando los corazones } & \text { que me miran a matar }\end{array}$

\footnotetext{
${ }^{3}$ La vinculación de las mujeres con el culto a los mártires, fenómeno fundamental del cristianismo a partir del siglo IV d. C., tiene sus antecedentes "en el cuidado y rituales para con los muertos, tanto familiares como públicos, del mundo pagano" (Pedregal, 1999: 60). Según esta autora, a las mujeres correspondían una serie de prácticas marginales, de carácter periférico respecto a la vida y la actividad del ciudadano, y consideradas arriesgadas y contaminantes, asociadas a preparar el nacimiento (los que van a nacer) y honrar a los muertos (los que ya no están). Con el triunfo del cristianismo estas prácticas tienen su continuidad, entre otras, en el culto a los mártires, que aún hoy se mantiene en gran medida. Lo cierto es que, como señalan Mary Nash, Ma José de la Pascua y Gloria Espigado, el monopolio que las mujeres tuvieron sobre las ceremonias relacionadas con la muerte primero, y con ésta y el culto a los mártires después, permitió a las mismas no sólo la profundización en sus creencias religiosas (...), sino también un aumento de las iniciativas desplegadas por ellas en un espacio hasta entonces masculino" (1999: 14). Esta línea de investigación marcada por estas autoras puede generar interesantes interpretaciones en torno a la mayor religiosidad de las mujeres que se desprende de la lectura de la etnografía sobre el ritual de Jarramplas. Sobre este mismo asunto escribe Teresa del Valle, autora que señala que el peso simbólico de la mujer "Se expresa principalmente en sus funciones rituales vinculadas al momento de la muerte" (1997: 12).

${ }^{4}$ Estas metáforas a veces asocian partes de un instrumento a una mujer, como la copla que llama a las cuerdas de la guitarra con nombres de éstas. Igualmente se utiliza alguna vez el simil: la prima (primera cuerda de la guitarra) parece el corazón de una niña, o pelos rubios de una mujer que sirven como cuerdas de guitarra.
} 
Las relaciones de poder dentro de una pareja quedan perfectamente marcadas en muchos textos en los que se pone de relieve la actitud pasiva y subordinada de la mujer frente al liderazgo y conducta activa del hombre, que es, en última instancia y en una situación de galanteo, al que corresponde la toma de decisiones importantes. A la mujer le corresponde esperar sumisa a que algún hombre se fije en ella y se lo haga saber con música o simbólicamente en el marco de ritos como el de la enramá en la noche de San Juan. Además en estos textos se refleja claramente el valor de la mujer como propiedad material de un hombre, bien de un novio, de un marido o de un padre, que la tiene en su poder o puede "darla" (caso del padre), siempre bajo el amparo de las leyes que así lo permiten. Como propiedad material en algunos textos se llega a poner un precio para cada mujer.

\author{
Capullito, capullito, \\ ya te estás volviendo rosa \\ ya se va acercando el tiempo \\ de decirte alguna cosa

A la luna de enero
le falta un día
y a ti te falta un año
para ser mía
Una rubia vale un duro
una morenita dos
yo me voy a la morena
aunque me cueste un millón

\author{
María paloma mía \\ las palomas son del rey \\ y tu tienes que ser mía \\ porque lo manda la ley \\ ¡Ay, qué calle tan oscura! \\ ¡ay, qué oscuridad de calle! \\ ¡ay, qué niña tan bonita \\ si me la diera su padre! \\ Una rubia vale un duro \\ la morena dos reales \\ yo me tiro a lo barato \\ lo moreno es lo que vale
}

\author{
No porque te hayas casado \\ olvides mi buen querer \\ que puede ser que enviudes \\ y vuelvas a mi poder \\ Una rubia vale un duro \\ una morenita dos \\ yo me tiro a lo barato \\ rubia de mi corazón.
}

El protagonismo del hombre en la toma de decisiones sobre la elección de la futura esposa frente a la actitud pasiva de ésta queda bien patente en una copla característica de las rondas de Carnaval, periodo que queda definido como el momento propicio en el que las mujeres tienen permitido exhibirse, como si de una feria se tratara, a la espera de que algún hombre ponga sus ojos en ellas. Las similitudes entre esta situación y la de compra-venta de animales en ferias de este tipo son evidentes.

\footnotetext{
Ya vienen los carnavales

la feria de las mujeres

la que no le salga novio

que espere al año que viene
}

Nuevamente como ocurría en las canciones infantiles, los textos de las rondas suelen mostrar claramente las asimetrías en las ocupaciones de hombres y mujeres que nos hablan de un encapsulamiento de éstas a la esfera de lo doméstico (compra para la casa, bordar, llevar agua de la fuente a casa, lavar la ropa, la costura) y de ellos a lo público (labrador, carbonero, sereno, molinero, arriero, minero, aceitunero).

$\begin{array}{ll}\begin{array}{l}\text { Salga usted madre } \\ \text { con el dinero, } \\ \text { compre carbones } \\ \text { al carbonero }\end{array} & \begin{array}{l}\text { Cuando mi novia se pone } \\ \text { a la ventana a bordar } \\ \text { ella borda pajaritos } \\ \text { y yo los hecho a volar }\end{array} \\ \begin{array}{l}\text { Paso río paso fuentes } \\ \text { siempre te encuentro lavando lavandera } \\ \text { de mi vida }\end{array} & \begin{array}{l}\text { A esas niñas costureas, } \\ \text { de esas que cosen pa fuera, } \\ \text { lu me vas enamorando venimos a cantar, } \\ \text { lesue tengan mucho cuidado } \\ \text { no se dejen clavada } \\ \text { la aguja en el delantal }\end{array} \\ \end{array}$

Vas a por agua a la fuente y no llevas compañía ¿quieres que yo te acompañe hermosa paloma mía?

Dicen los segadores que van segando quién bebiera tu agua Fuente Castaño 


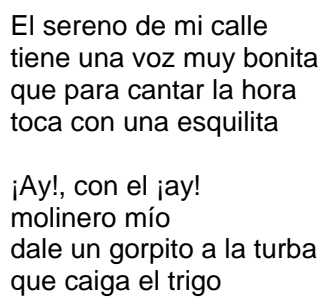

\author{
Los labradores \\ por la mañana \\ el primer surco \\ es por su dama \\ Quiéreme que soy minero \\ de las minas de la sal \\ y si te casas conmigo \\ te han de llamar salá
}

\author{
Eres arrierito \\ de cinco mulas \\ tres y dos son del amo \\ las demás tuyas \\ Madre yo tengo un novio \\ aceitunero \\ que vareando tiene \\ mucho salero
}

No podemos olvidar la ingente cantidad de coplas que sitúan a los hombres en la calle, moviéndose de un sitio para otro, haciendo vida pública, en una posición activa y de toma de decisiones respecto a la mujer, que se sitúa dentro de la casa, en la esfera de lo privado, esperando la presencia del hombre, pero casi nunca yendo a buscarla. En el caso de que fuese ella la que tomara la decisión de salir para encontrarse con el hombre, ello debía ocurrir en un lugar los más recóndito posible, lejos de la mirada de cualquier extraño (como dice una copla, "debajo del puente"). Algunos de estos textos nos hablan, como en los anteriores, de ocupaciones tradicionalmente masculinas ligadas a la esfera de lo público y de la presencia de mujeres en algunas de ellas (caso de la agricultura en épocas de recolección).

Yo venía de regar
y estabas a la ventana
me hiciste una señita
que estabas sola, que entrara
A verte vengo de noche
porque de día no me vaga
que estoy cortando pimientos
en Sierra de Bacanada
Vengo de la mar salada
vengo de la isla de Cuba
vengo de ver las cubanas delgaditas de
cintura

Carretero carretero vente juntito a mi vera que en la ventana de enfrente una morena te espera

Ferrocarril puente de hierro por los raíles se va mi dueño

Esta noche ha llovido mañana hay barro

cuatro pares de mulas tiran mi carro quítate niña de esos balcones

\author{
Mi carbonero \\ no vino anoche \\ y le estuve esperando \\ hasta las doce \\ Debajo del puente \\ hay una morena \\ que está esperando a su novio \\ que viene de la verbena \\ Quítate de esa ventana \\ no me seas ventanera \\ que la cuba de buen vino \\ no necesita bandera
}

En la ventana eres dama

En el baile una señora

y cuando sales al campo

una hermosa labradora

Son generalmente canciones de pique, muy características en las rondas de Carnaval, las que llevan las diferencias a sus extremos, diferencias que nuevamente nos remiten a los modelos tradicionales de género.

\author{
En este pueblo no hay mozas \\ y si las hay no las veo \\ que estarán en la cocina \\ atizando los pucheros
}

\author{
Te tienes por buena moza \\ por bailarina en el baile \\ y llegando a la cocina \\ ya no tenemos a nadie
}

Allá va la despedida con el farol en la esquina los hombres en la taberna la mujer en la cocina

Aún podríamos continuar este paseo por los textos de la tradición oral asociada a las canciones y el tratamiento que en ellas se da a la construcción de identidades de género, adentrándonos en los Romances, cantos narrativos que igualmente nos sitúan en modelos de género tradicionales en los que las asimetrías entre hombre y mujeres son evidentes y ciertamente marcadas, y que no vamos a comentar pues solo este análisis nos daría para otro artículo bien denso. 


\section{El folklore musical y su papel en la transformación de modelos de género}

En todo caso y al margen de lecturas ideológicas, más o menos críticas, que podamos hacer de estos textos, algo que nos interesa recalcar en este artículo es el valor de enculturación de la tradición oral, contribuyendo a la transmisión de modelos de género propios de una época y la sociedad que los generó.

Ciertamente las categorías de hombre y mujer que se muestran en los textos de canciones tradicionales acaban imponiéndose como realidades, proponiendo un orden y confiriéndoles un fundamento que hace concebirlas como algo natural. Estas categorías, musicalmente establecidas y reforzadas, en el ámbito social son de importancia primaria en tanto en cuanto determinan posiciones, relaciones y límites a éstas, pero, aunque percibidas como categorías naturales, no lo son en absoluto; como recogimos en la introducción, son categorías socialmente construidas y, añadimos, mantenidas mediante diversas estrategias, entre las cuales es muy importante señalar el valor de la música como elemento de transmisión, reproducción y afianzamiento de formas de vida: comportamientos, actitudes, creencias, modelos...

Ahora bien, de igual manera que la música con sus textos es capaz de consolidar estructuras sociales, caso de los modelos tradicionales de género, igualmente puede ayudar, de manera decisiva, a hacerlas tambalear y caer. Son los pueblos los que crean esa música y la utilizan en uno u otro sentido, siempre con el poder de la palabra, en este caso cantada, bien como ancla de estabilidad, de mantenimiento de las estructuras, de orden social, de idea de continuidad y comunidad, bien como motor de cambio, de inestabilidad, desorden y transformación de estructuras.

En este sentido es necesario abundar en algunas situaciones actuales o recientes que remiten a los mencionados procesos de cambio. Es el caso, por ejemplo, de las transformaciones que ha sufrido la idea misma de ronda, originariamente vinculada a actos sociales exclusivamente masculinos. Musicalmente, una canción de ronda se asociaba a una tonada nocturna de enamorados, y la ronda propiamente dicha, al acto de rondar a la moza galanteada, recorriendo calles y cantando coplas. En la segunda mitad del siglo XX esa acepción original, que nos habla de una mujer de actitud pasiva frente a la actitud activa del varón, poco a poco fue dejando de ser privativa del concepto de ronda, que en los últimos tiempos se ha visto ampliado a otros momentos y ocasiones. Así, también se denomina ronda a las veladas de canción y divertimento que celebraban y aún hoy celebran en ciertos lugares, mozos y mozas, generalmente vinculadas a contextos festivos: carnavales, despedidas de soltería, fiestas patronales, etc.

Por otro lado está el hecho de que si bien muchas canciones presentan textos en los que queda delimitado claramente quién debe cantarlas y a quiénes van dirigidas, en la actualidad es este un aspecto que se suele obviar en muchas interpretaciones, pudiendo encontrar textos atribuibles a un hombre cantados por mujeres e igualmente, aunque en una menor proporción por lo escaso de este 
repertorio, textos propios de mujeres interpretados por hombres. En algunos casos esto es posible transformando los morfemas de género en las letras de algunas canciones, algo que se hace sin ningún problema y que de alguna manera tiende a superar las asimetrías pregonadas y trasmitidas en otro tiempo.

Estamos hablando pues de que tanto los textos, como los contextos se están alterando en la dirección que marca la sociedad que los crea y recrea.

\section{Bibliografía}

Barcia Mendo, Enrique, Coord. (2004). La tradición oral en Extremadura. Badajoz: Junta de Extremadura.

Barrios Manzano, Mํ del Pilar (2004). Fuentes y metodología para el estudio de la música de tradición oral en Extremadura. Fregenal de la Sierra (Cáceres): Federación Extremeña de Folklore.

Brandes, Stanley (1991). Metáforas de la masculinidad. Sexo y estatus en el folklore andaluz. Madrid: Taurus.

Bullen, Margaret (1997). Identidad y género en los Alardes de Hondarrabia e Irán. Ankulegi, 1: 37-40.

Capdevielle, Ángela (1969). Cancionero de Cáceres y su provincia. Cáceres: Diputación Provincial de Cáceres.

Del Valle, Teresa (1997). "El género en la construcción de la identidad nacionalista", Ankulegi, 1: 922.

Flores del Manzano, Fernando (1996): Cancionero del Valle del Jerte. Jaraíz de la Vera (Cáceres): Asociación Cultural Valxeritense.

Gala González, S. (1999). Trabajo y prestigio de las mujeres en dos parroquias rurales gallegas. Tradición y cambio social en los albores del nuevo milenio. En Antropología Social y Antropología Feminista. Actas del VIII Congreso de Antropología. C. Díaz, y M. L. Esteban, Coords. Santiago de Compostela: FAAEE.

García Matos, Manuel (1944). Lírica Popular de la Alta Extremadura. Madrid: Unión Musical Española Editores.

Gil García, Bonifacio (1931). Cancionero popular de Extremadura. Badajoz: Centro de Estudios Extremeños. 
Gilmore, D.D. (1994). Hacerse hombre: concepciones culturales de la masculinidad. Barcelona: Piados.

Gregorio Gil, C (1999). Un análisis de la emigración internacional desde la antropología del género.

En Antropología Social y Antropología Feminista. Actas del VIII Congreso de Antropología. C.

Díaz, y M. L. Esteban, Coords. Santiago de Compostela: FAAEE.

Gutiérrez Lima, M. E. (1999). Mujeres y generaciones: un tejido para el cambio desde 'lo femenino'. En Antropología Social y Antropología Feminista. Actas del VIII Congreso de Antropología. C. Díaz, y M. L. Esteban, Coords. Santiago de Compostela: FAAEE.

López García, Julián (2002). Ideologías y ritos populares. Ciudad Real: Diputación de Ciudad Real.

Martín Muñoz, G., Ed. (1995). Mujeres, democracia y desarrollo en el Magreb. Madrid: Fundación Pablo Iglesias.

Méndez, L. (1991). Reflexiones sobre la poco común producción de las pequeñas mujeres. En Antropología de los Pueblos de España. Joan Prat et al., Eds. Madrid: Taurus.

Moreno Navarro Isidoro (1991). Identidades y rituales. Estudio introductorio. En Antropología de los Pueblos de España. Joan Prat, Ed. Madrid: Taurus.

Mozo González, C. (1992). Incorporación de las mujeres al espacio de los hombres y construcción social del género. En Anuario Etnológico de Andalucía 1992/1993. Sevilla: Consejería de Cultura y medio Ambiente / Junta de Andalucía.

Nash, M., Pascua, M.J. de la y Espigado, G., Eds. (1999). Pautas históricas de sociabilidad femenina. Rituales y modelos de representación. Cádiz: Universidad de Cádiz.

Otegui, Rosario (2001). Tiempos, espacios y actividades de las mujeres rurales. En La mirada cruzada en la Península Ibérica. María Cátedra, Ed. Madrid: Catarata.

Provanzal, D. (1999). La construcción del 'nosotras' o cómo las mujeres magrebíes se piensan y representan en sí mismas. En Antropología Social y Antropología Feminista. Actas del VIII Congreso de Antropología. C. Díaz, y M. L. Esteban, Coords. Santiago de Compostela: FAAEE.

Rodilla León, Francisco (2003). Música de Tradición Oral en Torrejoncillo. Cáceres: Institución Cultural El Brocense de la Diputación de Cáceres. 
Talego Vázquez, Félix (1996). Jerarquización social, dominación masculina y moral sexual en la Sierra Onubense. El caso de Aroche. Demófilo: 37-62.

Talego Vázquez, Félix (1999). Sexualidad femenina y patrimonio familiar en la Sierra Morena onubense. En Antropología Social y Antropología Feminista. Actas del VIII Congreso de Antropología. C. Díaz, y M. L. Esteban, Coords. Santiago de Compostela: FAAEE.

Thurén, B. M. (1992). Del sexo al género. Revista de Antropología, 2: 46-55.

\section{Preguntas de la editora}

1. Usted categoriza el modelo tradicional de género en términos de las dicotomías producción I reproducción y público / privado. No obstante a lo largo del texto hace referencia a autores que analizan prácticas productivas y prácticas públicas de las mujeres en distintos contextos. En el desarrollo de los estudios de género las dicotomías universalistas y abstractas han sido puestas en cuestión a través de trabajos etnográficos que ponen el énfasis en la variabilidad de los casos concretos. Con sus datos etnográficos ¿podría hablarse de una variabilidad de mujeres I modelos de género?, ¿hay dentro de las canciones representaciones de la mujer en labores productivas ylo públicas? ¿cuál podría ser la interpretación de estos ejemplos, de su escasez o su ausencia?, ¿qué relación encuentra entre el "modelo" que se explicita parcialmente en las canciones populares y las "prácticas" concretas de la Extremadura rural del siglo XX?

Tanto en la investigación etnomusicológica que ha originado este artículo, como la llevada a cabo en torno al ritual festivo de Jarramplas, de las que hablamos en la última pregunta, se pone de manifiesto la variabilidad mujeres/modelos de género en diferentes niveles. Existen cambios en los modelos de género en función de parámetros como el tiempo (en nuestra zona de estudio estos cambios son evidentes a partir de los años ochenta), la edad (las mujeres jóvenes han superado en cierto grado su asociación a las esferas de lo privado y la reproducción, cosa que no resulta tan evidente en el caso de las mujeres de más edad) y la ocupación (en las mujeres vinculadas -junto a sus padres y/o maridos- a la agricultura, que son la mayoría, se observa un cambio menor hacia la superación de modelos tradicionales de género que en las que tienen otras ocupaciones, caso por ejemplo de las funcionarias). No obstante, esta variabilidad no es tanta como podría pensarse, ya que, si bien es observable una tendencia al cambio hacia las simetrías de género en cualquiera de los niveles antes señalados, aún existe mayor similitud de la que cabría esperar a tenor de los profundos cambios sociales acontecidos en las últimas décadas, entre las mujeres de hoy y de ayer, entre las mujeres jóvenes y las mayores. Un ejemplo puede resultar esclarecedor de este hecho. El discurso de muchas mujeres jóvenes casadas nos habla por ejemplo de la libertad que les otorga el disponer de carné de conducir y de coche y el cambio que ello supone respecto a épocas anteriores; claro que luego añaden que fundamentalmente usan el coche para llevar o recoger a los niños del colegio los días de mal tiempo, o para desplazarse a Plasencia (ciudad cercana) a comprar comida a algún hipermercado, comprar ropa para los niños, llevarles al cine o al médico, lo que nos hace pensar más 
que el desvanecimiento del vínculo entre las mujeres y las esferas de lo reproductivo y lo doméstico, en su mantenimiento aunque con características diferentes.

Auque en un porcentaje muy pequeño, es cierto que podemos encontrar dentro de los textos de las canciones representaciones de la mujer en labores productivas y/o públicas, y ello en dos sentidos. Por un lado existe una tendencia relativamente moderna (años ochenta en adelante), a que las mujeres, cuando cantan en grupo, aún manteniendo las tonadas de las canciones, utilicen algunos textos adaptando la letra a su condición de mujeres. Son textos que de una manera especial resaltan las diferencias entre géneros y que tradicionalmente eran cantados por hombres. Por otro lado está el caso de textos de recambio nuevos, inventados recientemente y que sitúan a las mujeres en contextos antes asociados a hombres. Las canciones son las mismas, pero, en algunos casos los textos de recambio han variado siendo las mujeres el sujeto activo en ellos. Ilustramos esta respuesta con la siguiente copla transformada que puede escucharse en una ronda cuando todas las integrantes son mujeres: Allá va la despedida, la que dan las cereceras, cesta arriba cesta abajo, aquí están las piornalegas (la copla original habla de cereceros como hombres que se dedican a la recolección de cerezas, y a piornalegos como hombres de Piornal).

Como ya hemos sugerido al final del artículo, estos textos surgen asociados a una incipiente simetría entre los géneros. Los textos reflejan la realidad, es decir, el hecho de que las mujeres están superando en algún grado las diferencias sociales y culturales de épocas pasadas; su escasez nos habla asimismo de la misma realidad, la de que aún ese grado de acercamiento está muy lejos del que políticamente se quiere potenciar y dar a entender con casos como el de paridad en el gobierno de Zapatero: mismo número de ministros que de ministras. El artículo en su última parte, aún planteando algunos cambios que se están dando en el sentido comentado de transformación e invención de nuevas letras (muy escasas aún) con la mujer vinculada a lo productivo y lo público, sugiere la utilización del folklore musical en este sentido.

Los modelos tradicionales de género que reproducen las canciones populares son un fiel reflejo de la Extremadura rural del siglo XX, especialmente en su primera mitad y primeras décadas de la segunda. Es con la consolidación de las autonomías (entre ellas la extremeña) en los años ochenta y noventa, el papel aglutinador de la globalización en esta sociedad y las mejoras económicas evidentes en las zonas rurales (nuevos sistemas de producción o modernización de los anteriores, mejores vías de comunicación, políticas de desempleo, etc.) acontecidos en la última parte del siglo, con los que se pone en marcha ese camino hacia la igualdad entre hombre y mujeres, hecho que de la misma manera se inicia en el uso de los textos en determinadas canciones populares: creación de nuevos textos que apuntan al cambio y reconstrucción de antiguos.

2. En el artículo considera determinante el papel de la música de tradición oral en el mantenimiento de los modelos y propone que pueda también serlo en la transformación de los mismos. ¿Cuáles son las razones y medios que le dan al folklore musical dicho rol "determinante"? Posteriormente usted propone la incorporación de las mujeres a las "rondas" como el ejemplo de dichas transformaciones. Con anterioridad ha dado un ejemplo contrario 
referido a la no incorporación masculina a las canciones de los juegos tradicionales, a pesar de los esfuerzos coeducativos de los profesores. ¿Sugiere alguna interpretación a esta diferencia?, ¿hasta qué punto se está llevando a cabo la transformación del modelo y de su activación práctica en el folklore musical?, ¿qué papel juega la educación formal en la promoción de dicho cambio?, ¿cómo solventar las contradicciones entre su rol de transmisora de una herencia tradicional -juegos y canciones populares- y su labor coeducativa?

La implantación de la España de las autonomías, que ha revitalizado el folklore como recurso para su consolidación dado el poder de éste como elemento identitario (nombramiento y apoyo institucional de fiestas de interés turístico regional, creación del currículo extremeño en la educación obligatoria, apoyo al asociacionismo vinculado a la música tradicional, etc.), así como la resistencia a la voracidad de la globalización, con el mantenimiento a toda costa de referentes de identidad asociados a lo local en los cuales el folklore igualmente está teniendo un papel central, permiten pensar en ese rol determinante para la transformación otorgado al folklore. En España, frente a la idea de folklore como freno a la modernidad, idea muy arraigada en los años sesenta y setenta, a partir de esas décadas comienza a contemplarse como un recurso de inestimable valor para afianzar las autonomías y como escudo protector frente los excesos de la globalización, al margen de su interés turístico asociado a la "autenticidad", de esta manera ha pasado de ser algo a eliminar (modernidad versus folklore) a ser algo a potenciar y apoyar política y económicamente.

Respecto a la segunda pregunta, referida a la incorporación de las mujeres a las rondas y la no incorporación masculina a los juegos tradicionales con música, posiblemente estemos ante un caso más de asimetría. Tanto las canciones sociales infantiles, generalmente asociadas a juegos, como las canciones de mocedad entre las cuales situamos a las rondas, son ejemplos de canciones del ciclo de la vida. Las canciones han servido y sirven para marcar diferencias entre grupos de edad, y sirven igualmente para definir tránsitos entre unos y otros (tienen su papel en los ritos de paso). Este valor social les otorga un peso específico a la hora de determinar quienes pueden o deben cantar unas canciones y quienes no. La no incorporación masculina al repertorio musical y de juegos infantiles tradicionalmente femeninos puede alertarnos de la influencia de los adultos (padres, tíos, abuelos, etc.) para que la diferencia entre los géneros se mantenga. Es en los niños donde más resistencia se da al cambio (quizá habría que acudir también a la influencia de factores psicológicos, pero, sin duda, el influjo social y cultural es fundamental). Los niños en la construcción de su identidad, muchas veces influidos por los adultos, en gran medida realizan la oposición con el otro género, lo que les lleva a rechazar canciones y juegos del género opuesto; los jóvenes, por su parte, manifiestan su identidad más por oposición a los niños y a los adultos (oposición de edad) que por oposiciones de género, lo que les permite la asociación intergénero y a compartir canciones y conductas asociadas a estas. Hay un ejemplo que puede ayudarnos a ilustrar esta tesis. Es muy corriente que los grupos de folklore que existen en muchas localidades extremeñas posean su escuela infantil, a través de la cual van iniciando a niños en edad escolar para poco a poco irlos integrando en el grupo junto a los jóvenes y adultos. Pues bien, suele existir una diferencia importante en cuanto a la constitución del cuerpo de baile de los pequeños y los mayores, ya que en el primer caso la mayoría son niñas ("A los 
niños les da vergüenza" comentan ellas, "Bailan los maricas" es el discurso de ellos), mientras en el segundo la cosa se iguala.

Sobre la transformación del modelo podemos decir que la evidencia etnográfica nos habla de una transformación muy lenta, al menos en contextos rurales asociados a la agricultura, que es donde hemos realizado trabajo de campo, como lenta es la activación práctica en el folklore musical. Podríamos aseverar que estamos en un proceso de transición que camina despacio, pero que camina.

En cuanto al papel de la educación formal en este proceso de cambio, señalamos que la propuesta de coeducación impulsada con la reforma educativa de inicio de los años setenta, con órdenes como la presencia de niños y niñas en el mismo aula, supuso un revulsivo indudable hacia el cambio. A partir de entonces todas las reformas han incluido el tema de la igualdad entre los géneros como uno de sus aspectos centrales (por ejemplo la presencia en el currículo de los llamados temas transversales, entre los que se encuentra la educación para la igualdad entre los sexos). Pero todas estas propuestas pueden resultar papel mojado si los docentes o se implican en ellas, algo que ha ocurrido con gran frecuencia; su libertad de cátedra les permite ciertas libertades que pueden ir a favor o en contra de ellas. No son pocas las asociaciones que han denunciado el carácter sexista de la educación, sobre todo el lenguaje utilizado en libros de texto. Lo cierto es que la educación formal es quizá el principal arma contra la desigualdad de género, pero no el único, ya que no pocas veces este arma se vuelve contra la mano que la empuña, sirviendo más que para acercar posiciones, para alejarlas. Como docente en un Instituto de Educación Secundaria, observo una fuerte oposición al cambio proveniente de la acción ejercida por la educación recibida en familia, donde incluyo lo que los chicos "ven" en casa, resultando muy difícil, a veces totalmente infructuoso, luchar contra ella.

Entramos ahora en un tema importante y no carente de controversia. ¿Cómo mantener y valorar la tradición y a la vez criticarla y estimular su transformación?, ¿Cómo fomentar el conocimiento y la valoración de una tradición que nos presenta modelos de género que tienden a la diferenciación social entre hombres y mujeres y a la vez ejercer la crítica hacia esos modelos, promoviendo valores que caminen hacia la igualdad? Es una pregunta difícil de responder para la cual solo tengo algunas sugerencias.

Uno de los aspectos que no podemos perder de vista es el de la contextualización. Una canción, su melodía y su texto, tienen significado en un contexto determinado, por lo que, desde mi punto de vista, constituye un error la descontextualización. La música y los juegos populares que se trabajan en la escuela deben presentarse contextualizados. El niño debe saber cómo cantaban y jugaban sus padres y sus abuelos, debe practicar esas canciones y esos juegos, pero también debe saber por qué se cantaba y por qué se jugaba así, y a partir de ahí motivar la reflexión y la crítica positiva hacia una forma de vida que tuvo un significado en un momento concreto. Las canciones y los juegos populares no deben llegar a la escuela actual desnudos, sino vestidos y bien vestido con las galas sociales, culturales, políticas, económicas, religiosas, etc., que les vistieron cuando eran un componente 
esencial de la sociedad que los creó o los copió. Incluso, se puede motivar al niño a crear nuevos textos contextualizados en la sociedad actual.

Pienso que no es lícita la ausencia del folklore de los centros educativos porque este pueda a través de sus prácticas (canciones y juegos por ejemplo) preconizar unos valores (diferencias entre los géneros por ejemplo) que no son los que la actualidad prescribe, pero tampoco creo acertado introducirlo descontextualizado lo que puede llevar aparejados unos contenidos y unas formas en contradicción con las que preconiza la escuela actual.

3. ¿Podría detallar en mayor medida las especificidades técnico / metodológicas del artículo, así como las dificultades y opciones tomadas en la recogida y análisis de los datos? (Cuántas canciones recogió, de qué personas y contextos, cómo pudo periodizarlas, qué métodos utilizó para el análisis de contenido, etc)

Los contenidos etnográficos recogidos en este artículo forman parte de una investigación etnomusicológica más amplia realizada los últimos años de la década de los noventas y los primeros del presente siglo, en Piornal, una pequeña localidad extremeña de unos 1500 habitantes, en la que se recogieron y analizaron en torno a las 300 canciones de la tradición oral de este pueblo (unas 350 en total incluyendo versiones y variantes) y que pretende publicarse próximamente bajo el título Sonidos de un pueblo. Músicas, textos y contextos en Piornal. En dicho trabajo de recopilación de músicas mediante un trabajo de campo intensivo, con la entrevista y la observación como técnicas fundamentales, y el cuaderno y la grabadora como instrumentos básicos de recogida de información (también se acudió a algunas grabaciones realizadas en los años 60 del pasado siglo) aparecieron en torno a unas 600 coplas utilizadas en la actualidad como textos de recambio para diferentes canciones, además de los textos fijos de la mayor parte de las canciones. En el tiempo que duró la investigación se trabajó en diferentes contextos festivos y manifestaciones musicales en los que participaba gente de diferente edad, género, y condición social, además de mantener conversaciones, individuales y en grupo, también con gente muy diversa.

Con todo el material recogido se procedió a darle forma, estructurarle y analizarle. Se transcribieron todas las canciones con notación etnomusical, se clasificaron y ordenaron, se analizó su melodía, su ritmo y su forma, se buscó su presencia en otros cancioneros extremeños, etc.

En el proceso de transcripción de los textos y el trabajo comparativo con otros cancioneros extremeños, se obtuvo gran información de la forma de vida en sociedades rurales, como la piornalega y la extremeña en general, durante el pasado siglo: política, economía, sociedad, etc. En este artículo presentamos un análisis de textos en lo referente al ámbito de las relaciones de género, definidas fundamentalmente por las asimetrías, ámbito muy tratado en este tipo de literatura oral. 
En este mismo periodo de investigación, realizando la Tesis Doctoral sobre el ritual festivo de Jarramplas ${ }^{5}$ y la construcción de identidades de género (también de pueblo, de edad y de clase) en torno a esta fiesta, surgió la idea de cómo este ritual remite a lo más tradicional y a la vez a lo más moderno, es ancla y motor, defensor de principios y a la vez promotor de cambios, es un instrumento legitimador del orden social, subraya la idea de comunidad y de continuidad, es mecanismo simbólico de reproducción de un estado de cosas, de comunicación de que el mundo está ordenado y la comunidad unida, pero a la vez, refleja y expresa dinámicas de confrontación y cambio. En este sentido y en el ámbito del género, actualmente en la fiesta de Jarramplas, si bien se observa una tendencia a la reproducción de modelos de género tradicionales, están emergiendo con fuerza procesos de reorganización identitaria que la propia fiesta pone en marcha, de tal manera que Jarramplas, más que servir para perpetuar diferencias de género, lo hace para redefinirlas, es decir, se sitúa en propuestas anteriores para desde ellas promover el cambio. Podríamos decir que Jarramplas, apoyándose en una ideología de género previamente establecida, orienta a hombres y mujeres sobre nuevas concepciones que deben articular respecto al otro género.

Fue a raíz de este trabajo sobre Jarramplas unido a la gran cantidad de textos de las canciones de tradición oral que teníamos en nuestras manos, como surgió la pregunta ¿ocurrirá con la música algo similar a lo que acontece en la fiesta, es decir, una música que tradicionalmente ha servido para reproducir y reafirmar diferencias, puede en la actualidad incidir en que estas se atenúen?, pregunta sobre la que intenta dar algo de luz el presente artículo.

\footnotetext{
${ }^{5}$ La Tesis de título Jarramplas: ritual festivo y tramas de identidad en Piornal, codirigida por Julián López García (Universidad de Córdoba) y Rosario Guerra Iglesias (Universidad de Extremadura), fue leída en la Universidad de Extremadura en septiembre de 2004, obteniendo la calificación de sobresaliente cum laude. Los integrantes del tribunal fueron: Manuel Gutiérrez Estévez (catedrático de la Universidad Complutense) Honorio Velasco Maillo (catedrático de la UNED), Gerardo Fernández Juárez (Titular de la Universidad de Castilla-La Mancha), Ángel Díaz de Rada (titular de la UNED) y Domingo Barbolla Camarero (titular de la Universidad de Extremadura).
} 